\section{Dentin sialoprotein (DSP) transcripts: developmentally- sustained expression in odontoblasts and transient expression in pre-ameloblasts}

Ritchie HH, Berry JE, Somerman MJ, Hanks CT, Bronckers ALJJ, Hotton D, Papagerakis P, Berdal A, Butler WT: Dentin sialoprotein (DSP) transcripts: developmentally-sustained expression in odontoblasts and transient expression in pre-ameloblasts. Eur J Oral Sci 1997; 105: 405-413. (C) Munksgaard, 1997

Dentin sialoprotein (DSP), a $53 \mathrm{kDa}$ glycoprotein, is believed to be present exclusively in dentin. Using rat and mouse digoxigenin labeled (DIG)-DSP and ${ }^{35}$ S-DSP riboprobes, and in situ hybridization techniques, we have studied the presence of DSP mRNA at specific developmental stages of dentinogenesis. In mouse and rat molars and incisors, DSP transcripts were localized in young odontoblasts associated with early stages of predentin formation, as well as in mature odontoblasts, cells with cytoplasmic extensions embedded in the forming dentin. No DSP transcripts were detected in dental pulp, enamel organ, ameloblasts, epithelial root sheath, Meckel's cartilage, alveolar bone or tibia. Furthermore, no DSP mRNA was observed in other soft tissues including heart, lung, kidney, intestine, eye, and muscle. In addition to the intense and prolonged expression by odontoblasts, DSP mRNA was transiently expressed by pre-ameloblasts in both developing molars and incisors. These observations are consistent with the results of previous immunohistochemical studies (1). The transient expression of DSP in pre-ameloblasts across from young odontoblasts suggests an involvement of DSP in epithelial-mesenchymal interactions that are crucial to later stages of tooth development.
H. H. Ritchie ${ }^{1 *}$, J. E. Berry ${ }^{2}$, M. J. Somerman', C. T. Hanks ${ }^{3}$, A. L. J. J. Bronckers", D. Hotton", P. Papagerakis', A. Berdal', W. T. Butler'

'Department of Basic Sciences, University of Texas - Houston Health Science Center, Dental Branch, 6516 John Freeman Ave., Houston, Texas 77030 , ${ }^{2}$ Departments of Periodontics/Prevention/Geriatrics and Pharmacology, and ${ }^{3}$ Oral Medicine, Pathology and Surgery, University of Michigan, Ann Arbor, Michigan,

${ }^{4}$ Department of Oral Cell Biology, Academic Center for Dentistry in Amsterdam, Vrije Universiteit Amsterdam, The Netherlands, ${ }^{5}$ Laboratoire Biologie Odontologie, Institut Biomédical des Cordeliers, France

Helena H. Ritchie, Department of Pediatrics, 140 EMRB, lowa City, IA 52242, USA.

Telefax: +1-319-3354489

E-mail: helena-ritchie@uiowa.edu

Key words: dentin; odontoblasts; pre-ameloblasts; dentin sialoprotein

Accepted for publication June 1997
During dentinogenesis, a single layer of terminallydifferentiated odontoblasts secretes an extracellular matrix (ECM) comprised of type I collagen and non-collagenous proteins (NCPs). The initial, unmineralized ECM mineralizes to form dentin at a short distance from the periphery of the odontoblasts. It is believed that NCPs associated with dentin play a crucial role in controlling the mineralization process; however, the exact function of these proteins has yet to be determined (for reviews see (2-5)). Two important steps for potentially gaining insight into the function of these proteins

* Present address: Department of Pediatrics, University of Iowa, Iowa City, Iowa 52242, USA. are to examine whether they are odontoblastspecific and to determine their specific temporal expression patterns during tooth development.

Three distinct proteins have been reported to be dentin-specific: dentin phosphoprotein (DPP, also called phosphophoryn), dentin matrix protein-1 (Dmpl) and dentin sialoprotein (DSP). By immunolocalization, DPP was detected only in odontoblasts and dentin (6-8). In situ hybridization experiments, showed that Dmp1 was expressed in the mature secretory odontoblasts, and not in pre-odontoblasts or pulp cells (9). Recent data indicates that Dmp1 is not exclusively made by odontoblasts but is also expressed by osteoblasts and other tissues (D'Souza et al., unpublished). 
Dentin sialoprotein (DSP) is a $53 \mathrm{kDa}$, sialic acid-rich glycoprotein originally isolated from rat dentin $(10,11)$. The overall composition of DSP is similar to that of two bone sialoproteins, osteopontin (OPN) and bone sialoprotein (BSP). The sequence for DSP, deduced from $\mathrm{NH}_{2}$-terminal sequence analysis (11) and from the cDNA sequence (12), confirms this overall similarity in composition. However, there are no long stretches of amino acid sequence similarities in these three ECM proteins that would indicate derivation from a single ancestor gene; for example, DSP does not contain an Arg-Gly-Asp (RGD) sequence which is present in OPN and BSP, and which is directly involved in their cell attachment activity. Furthermore, DSP does not appear to promote cell attachment and spreading of fibroblasts and dental papillae cells in vitro (11).

A mouse partial DSP cDNA was generated from total RNA of CD-1 mouse incisors through RT-PCR, using rat DSP oligoprimers; the cDNA was subcloned into a pGEM7 vector and sequenced (13). The sequence of this partial DSP cDNA shared $91 \%$ similarity with that of the rat DSP cDNA, demonstrating conservation of DSP across two species.

Since the function of DSP is unknown, we have sought information on its spatial and temporal expression pattern during specific developmental stages, believing that these observations will provide valuable clues concerning its role during dentinogenesis. Extensive immunohistochemical studies (14) revealed that DSP is initially expressed by young odontoblasts, cells associated with early predentin formation. Intense DSP immunoreactivity was also detected in mature odontoblasts contiguous with mineralized dentin in odontoblastic processes and in the dentin matrix. Certain cells of dental pulp were also immunopositive, while in a large number of other cells and tissues, such as in enamel, bone, muscle, cartilage, and cementum, no DSP was detected. In a subsequent study (1), immunolocalization revealed that DSP was also present in pre-ameloblasts, cells programmed to differentiate into ameloblasts. This expression appeared transient because none of the other cells in the epithelial enamel organ were immunopositive, including ameloblasts. The pattern of DSP expression was clearly different from that of either collagen type I, osteocalcin or the amelogenins (1, 14). For example, immunostaining for osteocalcin and collagen type I was present only in the mesenchymal cells and not in the epithelial cells of tooth germs at any stage of development. Staining for amelogenins was seen in pre-ameloblasts, ameloblasts and enamel. Interestingly, amelogenins were transiently expressed in young odontoblasts.
The expression of DSP mRNA was studied by Northern blot analyses, which indicated multiple DSP transcripts in molar tooth germs and incisors. Consistent with the immunolocalization data, no DSP transcripts were detected in cells of other mineralized or soft tissues examined (12).

Immunolocalization assays detect the final protein product, but do not specify with certainty the cellular origin, while data obtained from Northern blots represent the expression of DSP transcripts in a mixed population of cells derived from a given tissue sample. Clearly, selective approaches are needed to identify those cells actively producing DSP transcripts. Preliminary data from in situ hybridization investigations in mouse and rat molars $(13,15)$ indicated expression of DSP mRNA exclusively in odontoblasts. In the present report, we describe the use of antisense and sense riboprobes to detect the expression of DSP mRNA at specific developmental stages in both rats and mice. We examined DSP mRNA expression in heads of newborn animals, and in jaws of animals at days $2,3,6,10,14,20$ and adult (greater than 4 months old), as well as in other tissues in both rats and mice.

\section{Material and Methods}

\section{Tissue preparation}

All rats were of the Sprague-Dawley strain. The jaws of newborn, 2, 6 and 7 day-old rats were excised and fixed in 4\% paraformaldehyde in PBS. The jaws of 10, 14, and 20 day-old and adult rats were fixed, then demineralized in $0.2 \mathrm{M} \mathrm{HCl}$ or in $15 \%$ EDTA and $0.5 \%$ paraformaldehyde. The tissues were extensively washed with PBS, dehydrated, cleared with xylene and embedded in paraffin.

CD-1 mouse tissue was obtained at specific developmental stages, including newborn (usually day 19), post-birth days $6,11,14,18$ and 22 and adult. Tissue was fixed using Bouin's fixative, decalcified for days $11,14,18,22$ and adult using acetic formyl saline (10\% acetic acid, $4 \%$ formaldehyde, $0.85 \%$ sodium chloride), and then dehydrated and embedded in paraffin. Alternatively, some CD-1 mouse tissues were prepared as cryosections, embedded in OCT compound (Baxter Diagnostics, Romulus, MI, USA), frozen, sectioned and then fixed in $4 \%$ buffered paraformaldehyde and either used immediately or dehydrated gradually and stored desiccated at $-70^{\circ} \mathrm{C}$.

Paraffin-embedded tissues were cut to a thickness of 5-7 $\mu \mathrm{m}$ and mounted on either Probe-on Plus microscope slides (Fisher Scientific, Pittsburgh, PA, USA) or on silane (3-aminopropyl-trimethoxy silane) treated slides. Cryosections were cut to a thickness of $10 \mu \mathrm{m}$ and were mounted on Probe on 
Plus slides. A total of 21 rats and 21 mice were used in these experiments.

\section{In situ hybridization}

Standard in situ hybridization procedures were used (16) with slight modifications for use with nonradioactive and radioactive probes, as noted below.

Probes - The $1.2 \mathrm{~kb}$ rat full-length DSP cDNA rDSP2 1176bp cDNA (12) and the 231 bp partial mouse DSP cDNA were cloned into pGEM-7z(+) vector $(12,13)$. T7 and SP6 promoters in this vector were utilized to generate antisense (AS) and sense (S) probes using the Genius-4 RNA Labeling Kit (Boehringer Mannheim, Mannheim, Germany) for non-radioactive digoxigenin (DIG) probes, or the Riboprobe Gemini II system (Promega, Madison, WI, USA) and in situ grade ${ }^{35}$ S-UTP (Amersham, Arlington Heights, IL, USA) for radioactive probes. DIG-labeled probes were treated with $0.1 \mathrm{~N} \mathrm{NaOH}$ to shorten them to approximately $200 \mathrm{bp}$. Radioactive probes were hydrolyzed at $60^{\circ} \mathrm{C}$, in $40 \mathrm{mM} \mathrm{NaHCO} / 60 \mathrm{mM}$ $\mathrm{NaCO}_{3}$ to a target length of $150 \mathrm{bp}$.

DIG hybridization - Paraffin sections were hydrated, then fixed with $4 \%$ buffered paraformaldehyde. Slides were washed in PBS, then treated with proteinase $\mathrm{K}$ (Ambion, Austin, TX, USA) $(2.5 \mu \mathrm{g} / \mathrm{ml}$ in $10 \mathrm{mM}$ Tris $\mathrm{HCl}, \mathrm{pH} 8.0,50 \mathrm{mM}$ EDTA) for $24 \mathrm{~min}$ at $37^{\circ} \mathrm{C}$, after which they were immersed in $0.2 \%$ glycine in PBS. Tissues were fixed again, then acetylated $(0.25 \%$ acetic anhydride in $0.1 \mathrm{M}$ triethanolamine, $\mathrm{pH} \mathrm{8.0)}$ ) and washed in PBS. Tissues were prehybridized using buffer ( $10 \mathrm{mM}$ Tris $\mathrm{HCl}, 0.3 \mathrm{M} \mathrm{NaCl}, 1 \mathrm{mM}$ EDTA, $\mathrm{pH} 7.5$ ) containing $50 \%$ formamide, $2 \times \mathrm{SSC}$ $(0.3 \mathrm{M} \mathrm{NaCl}, \quad 0.03 \mathrm{M}$ sodium citrate), $0.5 \times$ Denhardt's solution $(0.01 \%$ Ficoll, $0.01 \%$ polyvinylpyrrolidone, $0.01 \%$ bovine serum albumin), $100 \mu \mathrm{g} / \mu \mathrm{l}$ sonicated, denatured salmon sperm DNA, $0.4 \mathrm{mg} / \mathrm{ml}$ yeast tRNA and $0.5 \%$ SDS, incubating in a closed, humidified box at $50^{\circ} \mathrm{C}$ for $2 \mathrm{~h}$. DIG-labeled probes were added to an aliquot of the prehybridization solution at a concentration of $10-50 \mathrm{ng} / \mathrm{ml}$, and the mixture was heated at $100^{\circ} \mathrm{C}$ for $3 \mathrm{~min}$ and immediately cooled on ice. Prehybridization solution was removed from the slides, and $100 \mu \mathrm{l}$ of hybridization buffer was applied. Slides were overlaid with parafilm and were incubated overnight at $50^{\circ} \mathrm{C}$ in a humidified chamber. After incubation, slides were washed in $50 \%$ formamide in $2 \times \mathrm{SSC}$ at $60^{\circ} \mathrm{C}$, then rinsed and digested with RNase A ( $20 \mu \mathrm{g} / \mathrm{ml})$ and RNase $\mathrm{T} 1$ ( 10 units $/ \mathrm{ml}$ ), followed by another formamide-
SSC wash. Using the Genius nucleic acid detection kit (Boeringher Mannheim), sections were pretreated with $1 \%$ blocking agent in $0.3 \%$ Triton $\mathrm{X}-100$ and TBS (100 mM Tris $\mathrm{HCl}, \mathrm{pH} 7.5$, $150 \mathrm{mM} \mathrm{NaCl}$ ) (17), followed by incubation with conjugated anti-DIG antibody for $2 \mathrm{~h}$ at room temperature in a humidified chamber. After washing, color development was carried out overnight at room temperature in the presence of NBT (4-nitro blue tetrazolium chloride) and BCIP (5-bromo-4-chloro-3-indolyl-phosphate). Slides were then washed in $10 \mathrm{mM}$ Tris- $\mathrm{HCl}, 1 \mathrm{mM}$ EDTA, pH 8.0 and mounted with Glycergel (DAKOPATTS, Copenhagen, Denmark).

Radioactive hybridization - Paraffin sections were heated at $65^{\circ} \mathrm{C}$ for $20 \mathrm{~min}$, then treated with xylene and gradually hydrated, then digested with $10 \mu \mathrm{g} / \mathrm{ml}$ proteinase $\mathrm{K}$ in PBS for $30 \mathrm{~min}$ at $37^{\circ} \mathrm{C}$. Cryosections were gradually hydrated, foregoing treatment with heat, xylene, or proteinase $\mathrm{K}$. Cryo and paraffin sections were then acetylated, followed by gradual dehydration in ethanol. Hybridization was performed overnight at $50^{\circ} \mathrm{C}$ in a humid chamber, and tissue sections were overlaid with a hybridization solution containing $50 \%$ formamide, $1 \times$ hybridization buffer $(10 \mathrm{mM}$ Tris, $0.3 \mathrm{M} \mathrm{NaCl}$, $1 \mathrm{mM}$ EDTA, pH 7.5), $1 \times$ Denhardt's solution, $100 \mu \mathrm{g} / \mu \mathrm{l}$ sheared salmon sperm DNA, $500 \mu \mathrm{g} / \mathrm{ml}$ of tRNA, $10 \mathrm{mM}$ dithiothreitol (DTT), 10\% dextran sulfate, and $10^{6} \mathrm{cpm}$ of probe $/ 100 \mu \mathrm{l}$. After post-hybridization washes in $4 \times$ SSC, sections were treated with RNase A and then washed sequentially with decreasing concentrations of SSC containing $1 \mathrm{mM}$ DTT, finally incubating in $0.1 \times \mathrm{SSC}$ with $1 \mathrm{mM}$ DTT at $60^{\circ} \mathrm{C}$ for $30 \mathrm{~min}$. Following the high stringency incubation, slides were dehydrated quickly in ascending concentrations of ethanol, dried, and exposed to X-ray film for 1-3 days to determine efficiency of hybridization. Slides were then coated with NTB-2 emulsion from Kodak (Rochester, NY, USA) and stored in a dark desiccated container at $4^{\circ} \mathrm{C}$ for an appropriate time, determined by X-ray film results, usually 1 week to 1 month. Slides were developed using Kodak D-19 developer and rapid fixer, and were counterstained with hematoxylin/eosin.

\section{Results}

Using both DIG-DSP and ${ }^{35}$ S-DSP rat and mouse riboprobes, and in situ hybridization techniques, we have studied the expression of DSP mRNA at differing stages of tooth development. 


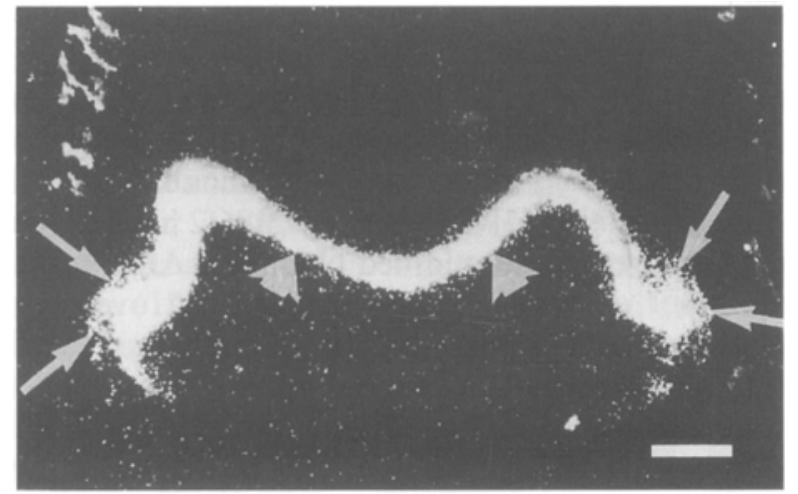

Fig. I. In situ hybridization of postnatal day 3 mouse molar using ${ }^{35} \mathrm{~S}$-anti-sense (AS) mouse riboprobe. Thin arrows: preameloblasts; bold arrowheads: odontoblasts. Note that the apparent positive signal in the upper left is background, not positive DSP transcripts. Magnification: $\times 100$. Bar $=100 \mu \mathrm{m}$.

\section{Developing mouse molars}

In the first molars of neonatal mice, DSP mRNA was detected in young odontoblasts, polarized cells associated with early predentin formation, before the onset of mineralization and in odontoblasts (not shown). At postnatal day 3, DSP transcripts were highly expressed in odontoblasts contributing to the formation of the molar crowns (Fig. 1). DSP mRNA was also associated with pre-ameloblasts, cells of epithelial origin located just across from the young odontoblasts. In contrast, DSP transcripts were not expressed by ameloblasts, nor was any expression observed in dental pulp or in surrounding cells or tissues. In the context of this manuscript, we are using the term pre-ameloblast to designate a stage of differentiation slightly prior to that of a secretory ameloblast, the stage of development that involves secretion of an overt layer of extracellular enamel matrix and its initial mineralization. Pre-ameloblasts are located across from young odontoblasts, cells that are just beginning to secrete an extracellular matrix but are not associated with mineralized dentin. Odontoblasts are the cells that are actively secreting dentin extracellular matrix that is mineralized and which have cytoplasmic extensions embedded in the forming dentin.

From postnatal days 5 to 8 , root formation in mouse first molars is initiated, coincident with discontinuity of the epithelial root sheath (ERS), and at day 8 , cementogenesis begins. At this stage, DSP mRNA was strongly expressed by odontoblasts in the crown and in the forming root (not shown). In addition, pre-ameloblasts in these teeth reacted positively with the AS-DSP riboprobe, while other cells of the forming tooth, including ameloblasts, cementoblasts, and dental pulp cells were negative.
During days $11-22$, in first molars, crowns continue to develop; root formation progresses and early stages of tooth eruption are initiated. At day 11 (Fig. 2), day 14 (not shown) and day 18 (not shown) of postnatal development, DSP mRNA was strongly expressed in odontoblasts of this forming tooth. No DSP transcripts were detected in other cells associated with these stages of tooth development including surrounding osteoblasts, cementoblasts, and periodontal ligament cells. At day 22, DSP mRNA was detected with the AS-DSP riboprobes; DSP mRNA was associated with the root and crown odontoblasts (Fig. 3A). No DSP mRNA signals were detected in odontoblasts with the S-DSP riboprobe (Fig. 3B). In adult mouse, as first molar development proceeds, DSP transcripts were still readily apparent within odontoblasts (not shown).

\section{Developing rat molars}

The results for developing rat molars were similar to those observed in mouse. In first molar tooth
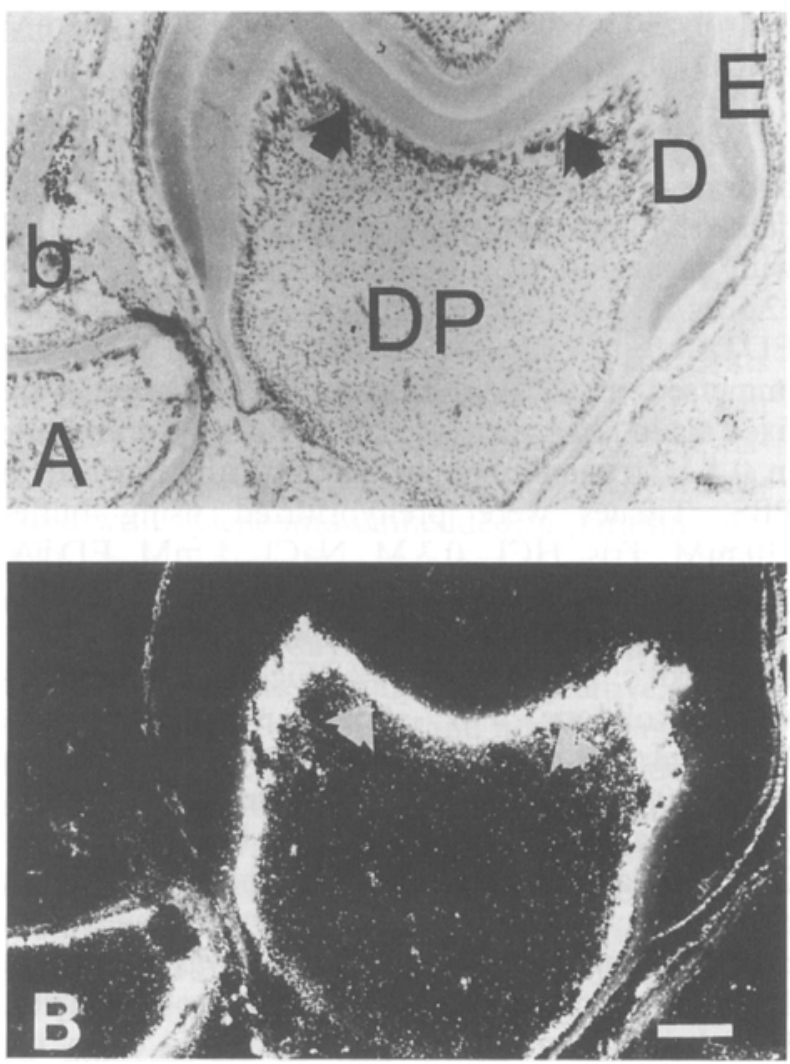

Fig. 2. Expression of DSP mRNA during rapid root formation in mouse molars. (A) light field: day 11 mouse molar. (B) dark field: ${ }^{35} \mathrm{~S}$-AS mouse DSP riboprobe for day 11 mouse molar. b: bone; D: dentin; E: enamel; DP: dental pulp; arrowheads odontoblasts. The apparent positive signal outside the enamel in B does not correspond to DSP mRNA but is background signal also present in sections treated with ${ }^{35} \mathrm{~S}$-sense $(\mathrm{S})$ riboprobes. Magnification: $\times 100$. Bar $=100 \mu \mathrm{m}$. 

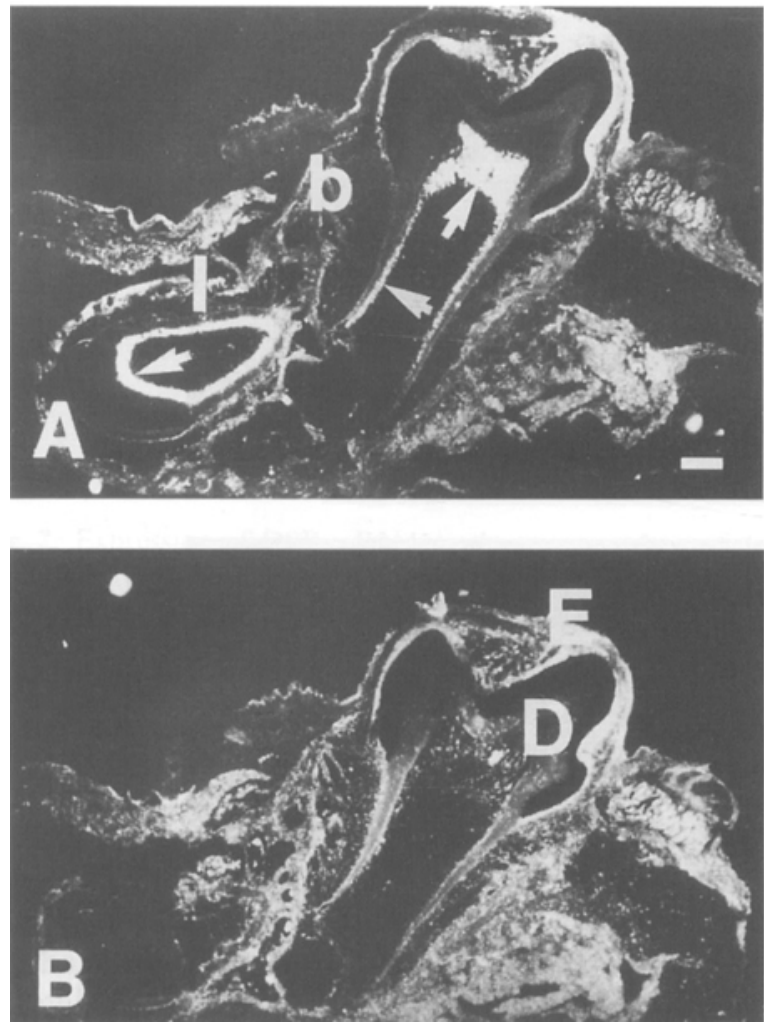

Fig. 3. Expression of DSP mRNA in mouse day 22 molar and incisor. (A) dark field: ${ }^{35} \mathrm{~S}$-AS mouse DSP riboprobe for day 22 mouse jaw. (B) dark field: ${ }^{35} \mathrm{~S}-\mathrm{S}$ mouse DSP riboprobe for day 22 mouse jaw. I: incisor; b: bone; arrowheads: odontoblasts; D: dentin; E: enamel. Magnification: $\times 20$. Bar $=100 \mu \mathrm{m}$.

germs of the neonatal rat, DSP transcripts were detected in young odontoblasts and in odontoblasts, the latter associated with forming dentin (not shown).

Using DIG-AS DSP riboprobes in the first molars of 2 day-old rats, DSP transcripts were observed in young odontoblasts and odontoblasts (18); DSP mRNA was also detected in odontoblasts of the second molar. Expression of DSP mRNA was also observed in the pre-ameloblasts in the apical areas of these forming teeth but not in ameloblasts. In these sections, no reactivity was detected in other cells, including osteoblasts and dental papilla fibroblasts. At postnatal day 3, DSP mRNA was expressed in odontoblasts of the maxillary first molars (Fig. 4); young odontoblasts and preameloblasts were also positive for DSP transcripts. Again, there was no evidence for DSP mRNA in other cells of these forming teeth, including dental pulp cells, ameloblasts or osteoblasts. The results obtained with DIG-DSP riboprobes were precisely the same as with ${ }^{35} \mathrm{~S}$-riboprobes (not shown).

From postnatal days 5 to 8 , root development of rat first molars progresses rapidly; discontinuity of the ERS occurs and at day 8, cementogenesis begins. At this stage of development, DSP tran-
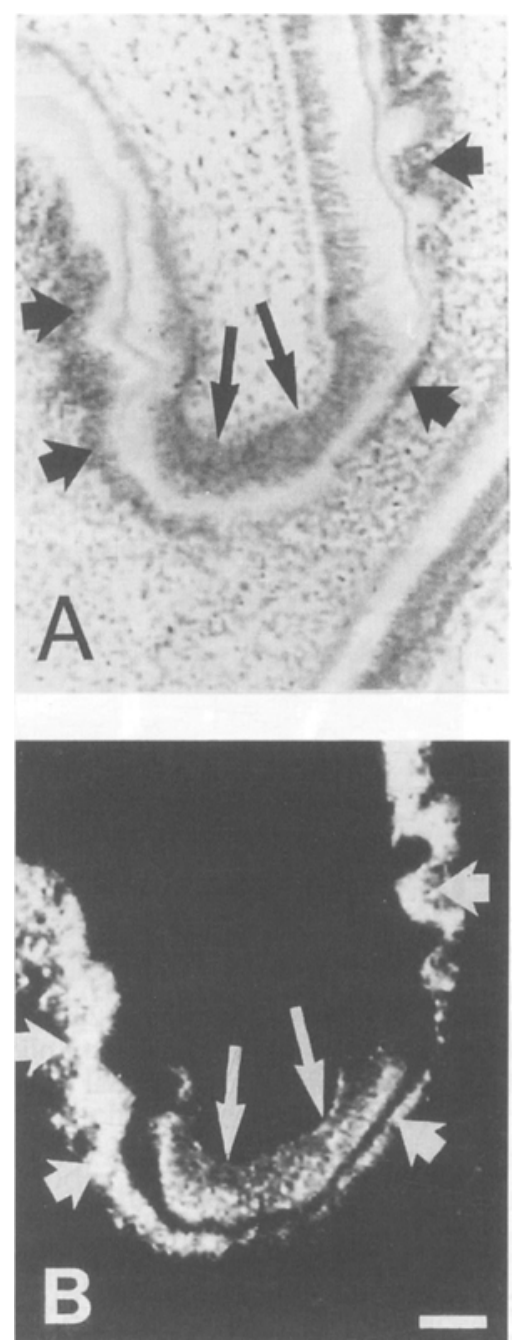

Fig. 4. Expression of DSP mRNA in postnatal day 3 rat jaw. (A) light field showing pre-ameloblasts (arrows) across from odontoblasts (bold arrowheads) in maxillary first molar. (B) dark field of (A), ${ }^{35} \mathrm{~S}$-AS rat riboprobe. Arrows point to the pre-ameloblasts and bold arrowheads to odontoblasts. Magnification: $\times 400$. Bar $=100 \mu \mathrm{m}$.

scripts were detected with ${ }^{35} \mathrm{~S}$-AS DSP riboprobes in odontoblasts in both the crown and root areas (not shown). Other tissues and cells associated with these teeth were negative.

During days 11-22, root formation continues to progress and the eruption process begins. In day 20 rats, odontoblasts of the first, second and third molars displayed expression of DSP mRNA (Fig. 5). Surrounding bone cells and those in dental pulp showed no evidence of DSP transcript expression. In adult rats (greater than 4 months old), the odontoblasts of first and second molars were positive for DSP mRNA expression (not shown).

\section{Rat incisors}

At postnatal day 3 in maxillary incisors, DSP transcript expression was observed in odontoblasts 

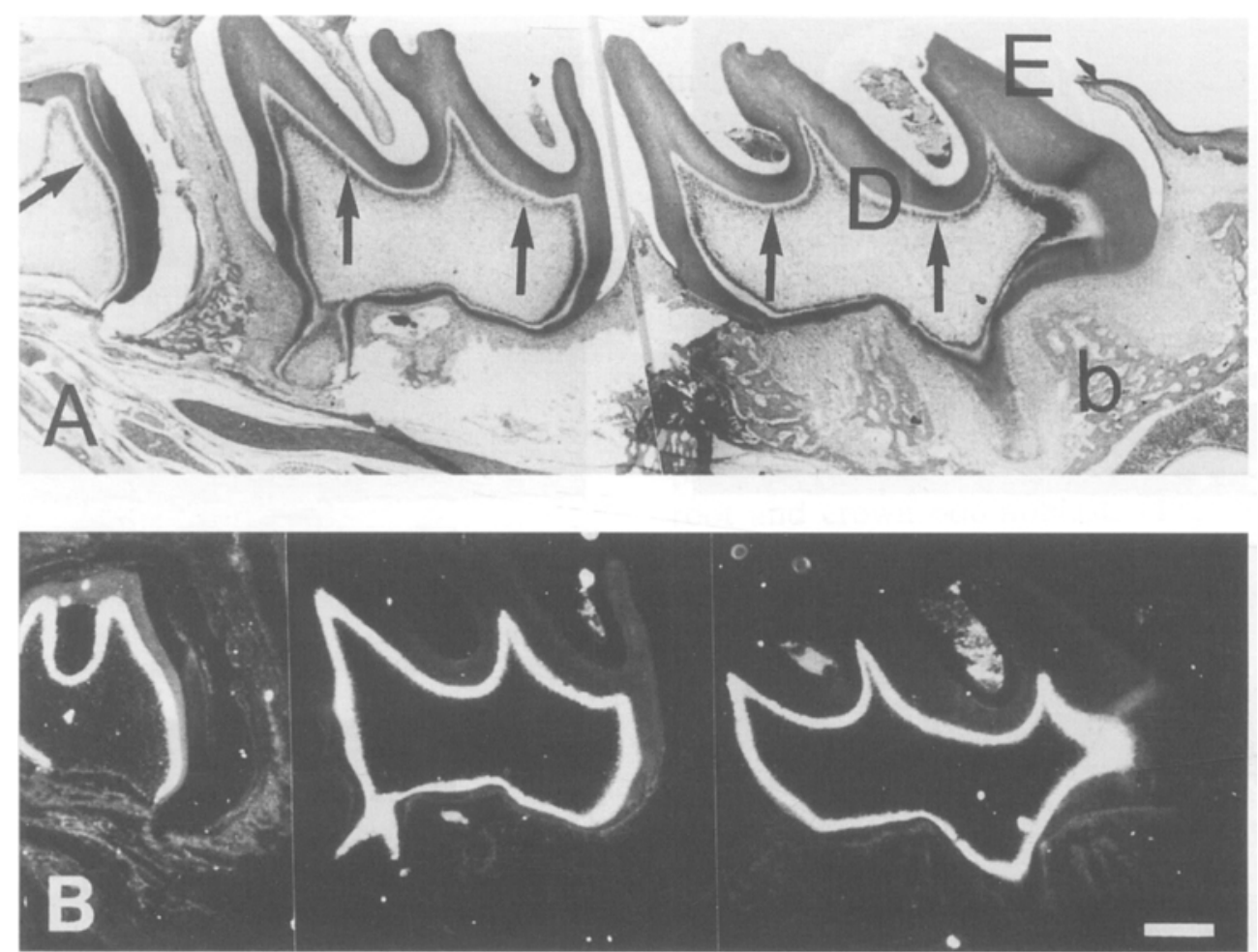

Fig. 5. Expression of DSP mRNA in day 20 rat molar teeth. (A) light field: day 20 rat jaw; arrows: odontoblasts; D: dentin; E: enamel, b: bone. (B) ${ }^{35}$ S-AS rat DSP riboprobe detected DSP transcripts in odontoblasts of the first, second and third molars (right to left order). Magnification: $\times 40$. Bar $=100 \mu \mathrm{m}$.

(Fig. 6), utilizing DIG-AS DSP riboprobes. As observed for molars, expression of DSP mRNA was detected in pre-ameloblasts while no expression was detected in ameloblasts, dental pulp or other tissues associated with these teeth.

In the dental mesenchyme of 15-day-old rat incisors, one can follow odontoblast differentiation along the epithelio-mesenchymal junction as these cells progressively lengthen and polarize (Fig. 7). In this tissue, DSP mRNA was expressed by young odontoblasts involved in secretion of the initial

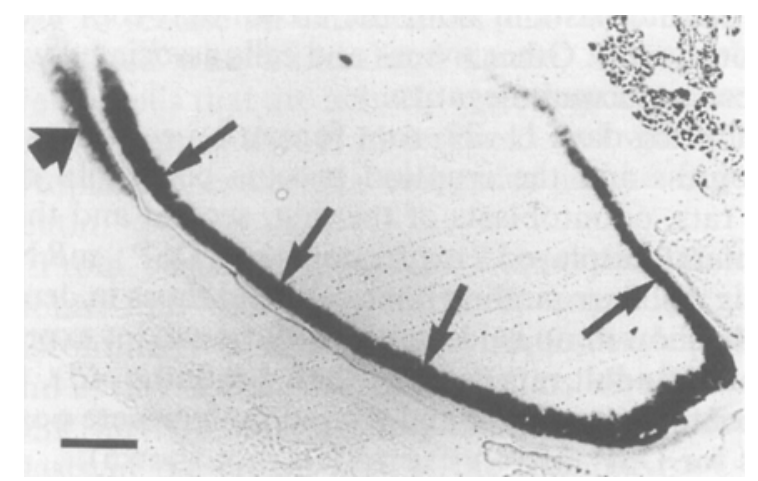

Fig. 6. Expression of DSP mRNA in day 3 rat incisor: DIG-AS rat DSP riboprobe detected DSP mRNA expression in preameloblasts (bold arrowhead) and odontoblasts (arrows). The apparent positive signals outside the incisor (upper right) are background. predentin (Fig. 7), but no evidence for DSP transcript expression was observed at earlier stages of odontoblast differentiation (not shown). In the epithelial portion of this tissue, pre-ameloblasts were positive for DSP transcripts; this expression was abruptly terminated as these cells further differentiated into ameloblasts involved in enamel formation (Fig. 7, thick arrow). In the dental mesenchyme of the root analogy of the 15-day-old rat incisor, expression of DSP mRNA was similarly observed coincident with the differentiation and maturation of odontoblasts; only cells beginning to secrete predentin were positive for DSP transcripts (not shown). DSP transcripts were not detected in the corresponding epithelial regions, nor in any other cell type associated with this tissue.

Active expression of DSP transcripts was also observed in odontoblasts of day 22 and of adult rat incisors (not shown). Alveolar bone and dental pulp cells of these teeth did not react with the AS-DSP riboprobes.

\section{Other organs and tissues}

We surveyed non-dental organs and tissues including the front and rear bodies of newborn rats, as well as kidney, heart, intestine, eye and lung of adult rats (not shown). No DSP mRNA was 


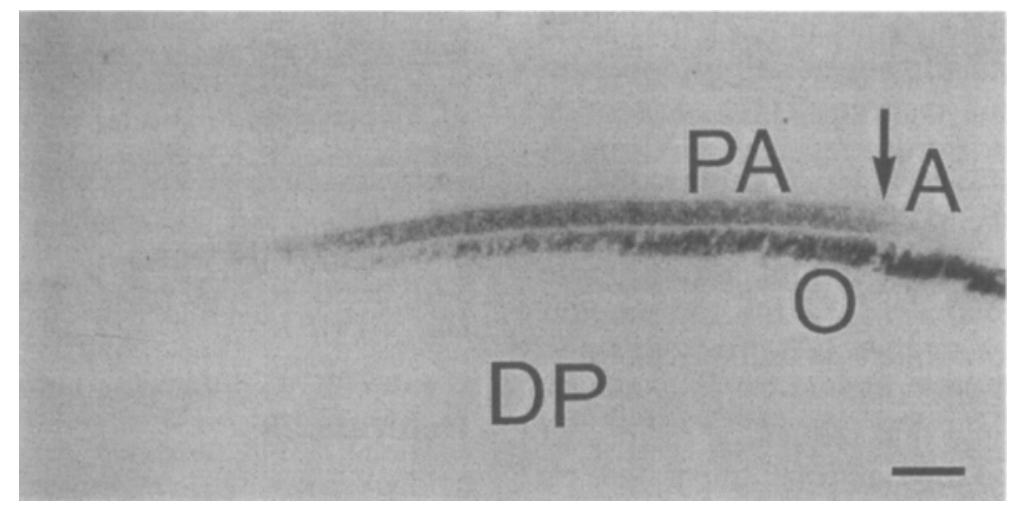

Fig. 7. Expression of DSP mRNA in the crown anlage of day 15 rat incisor with ${ }^{35}$ S-AS rat DSP riboprobe. Note the expression of DSP mRNA in pre-ameloblasts (PA), but not in ameloblasts (A). Adjacent odontoblasts (O) also expressed DSP transcripts while dental pulp (DP) was negative. Magnification: $\times 500$. Bar $=100 \mu \mathrm{m}$.

detected in these soft tissues. Also no DSP transcripts were detected in the adult tibiae, including hypertrophied chondrocytes and osteogenic marrow (not shown).

\section{Discussion}

We have utilized rat and mouse tooth organs from animals of a variety of ages to examine the localized expression of DSP mRNA at specific stages of odontoblast differentiation and tooth formation. Using DIG-DSP and ${ }^{35}$ S-DSP rat and mouse riboprobes and in situ hybridization techniques, we have demonstrated the presence of DSP mRNA in young odontoblasts, cells just beginning to secrete predentin but not associated with mineralized dentin, as well as in mature odontoblasts, cells with cytoplasmic extensions embedded in the forming dentin. This close physical association between DSP expression and forming dentin strongly suggests a role for DSP in dentinogenesis.

No DSP transcripts were detected in dental pulp, enamel organ, ameloblasts, Meckel's cartilage, alveolar bone or tibia. Also no DSP mRNA was detected in other soft tissues including heart, lung, kidney, intestine, eye, and muscle. These results complement our previous immunohistochemical studies $(1,4,19)$ where we demonstrated that these tissues were not immunopositive for anti-DSP antibodies.

We previously reported (4) that affinity purified anti-DSP antibodies stained cells in dental pulp at certain stages of tooth development. In contrast, no DSP mRNA was detected in dental pulp cells of mouse or rat at any of the stages of tooth development examined. The reasons for the apparent discrepancy between the in situ hybridization and immunohistochemical results are unclear. Proteins present in dental pulp may contain epitopes similar to those in DSP that are recognized by anti-DSP antibodies.
In addition to the intense expression of DSP transcripts by odontoblasts, pre-ameloblasts also reacted strongly with the DSP antisense probes. More specifically, the in situ hybridization data showed that (a) DSP mRNA was expressed by preameloblasts; (b) DSP mRNA was expressed by young odontoblasts across from these cells; (c) within a narrow time window (i.e., between the appearance of first predentin and that of the first enamel), DSP mRNA was expressed in both epithelial and mesenchymal cells; and (d) expression of DSP mRNA ceased when pre-ameloblasts were fully differentiated into secretory ameloblasts. During the latter time frame, DSP mRNA expression continued in odontoblasts (i.e., odontoblasts expressing DSP mRNA were adjacent to nonexpressing ameloblasts; see Fig. 7). These observations that DSP transcripts are transiently expressed in pre-ameloblasts are consistent with those from our earlier immunolocalization studies showing that pre-ameloblasts are immunopositive for DSP (1). At that time, we hypothesized that preameloblasts synthesized DSP. Since the origin of DSP could not be determined immunologically, an alternative possibility was offered: pre-ameloblasts might not synthesize and secrete DSP but they may take it up from adjacent predentin by a process of endocytosis. Another possibility considered was that pre-ameloblasts synthesize a product that is antigenetically related to DSP. The two studies on expression of DSP mRNA and DSP protein indicate that pre-ameloblasts, in fact, transcribe and translate DSP mRNA and that this newly synthesized DSP is then secreted in a stage-specific manner.

The precise rôle(s) of DSP during dentinogenesis is unclear. DSP may be a structural ECM protein, involved in modulating hydroxyapatite formation (20). Alternatively, DSP could act as a signal transduction molecule like other matrix proteins 
such as fibronectin (21) or tenascin (22). The sialic acid rich proteins from rat bone (i.e., osteopontin and bone sialoprotein) contain RGD sequences; these proteins are able to transduce signals through integrins on cell surfaces to influence cell behavior (23-25). Since DSP does not contain an RGD sequence (12) and apparently does not promote cell attachment in vitro (11), the interaction between DSP and odontoblasts is unlikely to function through the integrins.

It is generally accepted that sequential reciprocal epithelial-mesenchymal interactions, mediated by the extracellular matrix (i.e., the dental basement membrane and predentin/dentin matrix), lead to the differentiation of odontoblasts and ameloblasts (26). Our in situ hybridization data provide some insights concerning the potential role of DSP during dentinogenesis. The transient expression of DSP in pre-ameloblasts and the co-expression of DSP mRNA in both pre-ameloblasts and odontoblasts suggest that DSP might have a role during epithelial-mesenchymal interactions. DSP secreted by preameloblasts could be involved in triggering further odontoblast differentiation which leads to the activation of the odontoblast synthetic machinery. We hypothesize that a signal molecule secreted by pre-odontoblasts initiates the DSP expression by pre-ameloblasts and reciprocally, that the secretion of DSP molecules by pre-ameloblasts signals adjacent odontoblasts. The exact mechanisms for the initiation of DSP expression in pre-ameloblasts and later in odontoblasts are unknown. Further experiments are needed to examine these potential mechanisms.

Subsequent to completion of our studies on DSP mRNA localization, new data were obtained relating to the structure of DSP gene and mRNA. Studies of the $3^{\prime}$ region of rat DSP cDNA revealed (27) a nucleotide sequence juxtaposed to the DSP sequence that corresponded to dentin phosphoprotein (DPP). Furthermore, the same DSP and DPP arrangement was found in the rat genomic DNA (28). Recently, it was discovered that mouse DSP and DPP are expressed as a single continuous cDNA transcript with the $5^{\prime}$ region coding for DSP and with the DPP sequences in the $3^{\prime}$ end (29). This finding suggests that, localization of DSP and of DPP transcripts utilizing the appropriate probes should yield identical results. In fact, recent in situ hybridization experiments using mouse incisors indicate identical patterns of expression for DSP and DPP mRNA in pre-ameloblasts and odontoblasts (C Bègue-Kirn \& WT Butler, unpublished observations).

Acknowledgements - We thank Dr. David G. Ritchie for helpful discussion and contributions during the preparation of this manuscript. We thank Mr. Chris Strayhorn, Ms. Gillian Rittman and Ms. Verna Hubbard for excellent work in preparing tissue sections and Ms. Hou Hui for technical assistance. We also thank Dr. Catherine M. Flaitz for supplying us with tissue sections during our pilot experiments and Dr. Rena N. D'Souza for help with dark field microscopy. We would also like to thank Ms. Linda Jones for her assistance in the preparation of this manuscript. This work was supported by NIH grants R37 DE05092 (WTB), DE09532 (MJS) and DE11442 (HHR).

\section{References}

1. Bronckers AlJj, D'Souza RN, Butler WT, Lyaruu DM, VAN DiJK S, Gaywoltgens JH. Dentin sialoprotein: biosynthesis and developmental appearance in rat tooth germs in comparison with amelogenins, osteocalcin and collagen type-I. Cell Tiss Res 1993; 272: 237-247.

2. VeIS A. Mineral-matrix interactions in bone and dentin. J Bone Miner Res 1992; 8: 5493-5497.

3. Linde A, Goldberg M. Dentinogenesis. Crit Rev Oral Biol Med 1993; 4: 679-728.

4. BUTLER WT. Dentin matrix proteins and dentinogenesis. Connective Tiss Res 1995; 33: 59-65.

5. Butler WT, RitchiE HH. The nature and significance of dentin extracellular matrix proteins. Int J Dev Biol 1995; 39: $169-179$.

6. MacDougall M, Zeichner-David M, Slavkin HC. Production and characterization of antibodies against murine dentin phosphoprotein. Biochem $J$ 1985; 232: 493-500.

7. Gorter de Vries I, Quartier E, Van Steirtghem A, Boute P, CoOmans D, Wisse E. Characterization and immunocytochemical localization of dentine phosphoprotein in rat and bovine teeth. Arch Oral Biol 1986; 31: 57-66.

8. Rahima M, Tsay TG, Andujar M, Veis A. Localization of phosphophoryn in rat incisor dentin using immunocytochemical techniques. $J$ Histochem Cytochem 1988; 36: 153-157.

9. GeORge A, Silberstein R, Veis A. In situ hybridization shows Dmpl (AG1) to be a developmentally regulated dentin specific protein produced by mature odontoblasts. Connective Tiss Res 1995; 33: 67-74.

10. Butler WT, Bhown M, Dimuzio MT, Linde A. Noncollagenous proteins of dentin. Isolation and partial characterization of rat dentin proteins and proteoglycans using a three-step preparative method. Collagen Relat Res 1981; 1: 187-199.

11. Butler WT, Bhown M, Brunn JC, D'Souza RN, FarachCarson MC, Happonen R-P, SChrohenloher RE, SEYer JM, Somerman MJ, Foster RA, Tomana M, Van Dijk $S$. Isolation, characterization and immunolocalization of a 53-kDal dentin sialoprotein (DSP). Matrix 1992; 12: 343-351.

12. Ritchie HH, Hou H, Veis A, Butler WT. Cloning and sequence determination of rat dentin sialoprotein, a novel dentin protein. $J$ Biol Chem 1994; 269: 3698-3702.

13. Ritchie HH, Shigeyama Y, Somerman MJ, Butler WT. Mouse dentin sialoprotein(DSP): Partial cDNA sequence and specific expression by odontoblasts. Arch Oral Biol 1996; 41: 571-576.

14. D'Souza RN, Bronckers ALJJ, Happonen RP, Doga DA, Farach-Carson MC, Butler WT. Developmental expression of a $53 \mathrm{kD}$ dentin sialoprotein in rat tooth organs. J Histochem Cytochem 1992; 40: 359-366.

15. Ritchie HH, Pinero GJ, Hou H, Butler WT. Molecular analysis of rat dentin sialoprotein. Connective Tiss Res 1995; 33: 395-401. 
16. Ausubel FM, Brent R, Kingston RE, Moore DD, Seidman JG, SMith JA, Struhl K. In situ hybridization and immunohistochemistry. In: Current protocols in molecular biology. New York editors: Wiley-Interscience, 1992.

17. Bland YS, Critchlow MA, Ashrurst DE. Digoxigenin as a probe label for in situ hybridization on skeletal tissues. Histochem J 1991; 23: 415-418.

18. Butler WT, RitchiE HH, BronCKers ALJJ. Extracellular matrix proteins of dentine in dental enamel. $C I B A$ Foundation Symposium 205, New York: John Wiley \& Sons, 1997; 107-115.

19. Bronckers AlJJ, Farach-Carson MC, Van Waveren E, BUTLER WT. Immunolocalization of osteopontin, osteocalcin, and dentin sialoprotein during dental root formation and early cementogenesis in the rat. $J$ Bone Min Res 1994; 9: $833-841$

20. Boskey AL. Osteopontin and related phosphorylated sialoproteins: effects on mineralization. Ann New York Acad Sci 1995; 760: 249-256.

21. Thesleff 1, Mackie E, Vainio S, Chiquet-Chrismann R. Changes in distribution of tenascin during tooth development. Development 1987; 101: 289-296.

22. Thesleff I, Stenman S, Vaheri A, Timpl R. Changes in the matrix proteins, fibronectin and collagen during differentiation of mouse tooth germ. Dev Biol 1979; 70: 116-126.
23. Somerman MJ, Fisher LW, Foster RA, Sauk JJ. Human bone sialoprotein I and II enhance fibroblast attachment in vitro. Calcif Tissue Int 1988; 43: 50-53.

24. Somerman MJ, Prince CW, Sauk JJ, Foster RA, Butler WT. Mechanism of fibroblast attachment to bone extracellular matrix: Role of a $\mathbf{4 4}$ kilodalton bone phosphoprotein. $J$ Bone Min Res 1987; 2: 259-265.

25. Oldberg A, Franzen A, Heinegard D. Cloning and sequence analysis of rat bone sialoprotein (osteopontin) cDNA reveals an Arg-Gly-Asp cell binding sequence. Proc Natl Acad Sci USA 1986; 83: 8819-8823.

26. RuCH JV. Odontoblast differentiation and the formation of the odontoblastic layer. J Dent Res 1985; 64: 489-498.

27. Ritchie HH, WaNG L-H. Sequence determination of an extremely acidic rat dentin phosphoprotein. $J$ Biol Chem 1996; 271: 21695-21698.

28. RitchiE H, WANG L-H. A mammalian bicistronic transcript encoding two dentin-specific proteins. Biochem Biophys Res Commun 1997; 231: 415-428.

29. MacDougall M, Simmons D, Luan X, Nydegger J, FENG J, GU TT. Dentin phosphoprotein and dentin sialoprotein are cleavage products expressed from a single transcript coded by a gene on human chromosome 4. J Biol Chem 1997; 272: 835-842. 